\title{
Potential of fungi to produce biosandstone
}

\author{
Carolina Martuscelli ${ }^{1,2}$, Célia Soares ${ }^{2}$, Nelson Lima ${ }^{2}$, Aires Camões ${ }^{1}$ \\ 1 CTAC - Centre for Territory, Environment and Construction, University of Minho, Guimarães, Portugal, Campus of Azurém, $4810-058$ \\ Guimarães, Portugal \\ 2 CEB- Centre of Biological Engineering, University of Minho, Campus of Gualtar, 4710-057 Braga, Portugal
}

Received: 9 July 2020 / Accepted: 21 December 2020 / Published online: 30 December 2020

(C) The Author(s) 2020. This article is published with open access and licensed under a Creative Commons Attribution 4.0 International License.

\begin{abstract}
Over the last decade, microbial induced calcium carbonate precipitation (MICCP) has been used in several types of research due to its potential in applications for the areas of construction materials and geotechnics. Biotechnology into the area of building materials, has enabled the development of the so-called biomaterials of construction produced through biomineralization. Most of the biocementation studies to make biosandstones, biobricks or to promote bio self-healing on concrete present bacteria as the microorganisms responsible for the $\mathrm{CaCO}_{3}$ induction process. Fungi are potentially better for the biocementation process because they have more biomass and some develop filaments that can be used as microfibers on materials. Thus, the present work proposes the development of a methodology to analyse the potential use of two urease-positive fungi (Penicillium chrysogenum MUM 9743 and Neurospora crassa MUM 9208) to produce biosandstone. The microstructure and chemical constituents of biocrystals formed due to MICCP were observed under Scanning Electron Microscopy (SEM). SEM showed fungal mycelia as bio-based fibre in biosandstone and clusters of probable calcite crystals on and around mycelia. Despite the resistance obtained was up to 50-66 kPa until now, both fungi were able to promote biocementation of sand. More research is needed to increase the material resistance up to 1-2 MPa that is required for these building materials.
\end{abstract}

Keywords: Biosandstone; Microbiologically Induced Calcium Carbonate Precipitation (MICCP); Sustainable Solution; Fungi

\section{Introduction}

Some living organisms are capable to perform biomineralization, which is the synthesis of minerals as a result of biological activity. Calcium carbonate $\left(\mathrm{CaCO}_{3}\right)$ is the most common product of biomineralization processes and calcite precipitation is considered the most frequent phenomenon of mineral formation by the action of microorganisms in nature [1-3].

Most biomineralization processes are carried out through biologically induced mineralization. In this type of process, the microorganism changes its local microenvironment to create suitable physical-chemical conditions for mineral precipitation [1,4].

The microbiologically induced $\mathrm{CaCO}_{3}$ precipitation (MICCP) results from several metabolic processes, the main ones being photosynthesis, denitrification, sulphate reduction, metabolic conversion of calcium salts, and ureolysis (urea hydrolysis). However, $\mathrm{CaCO}_{3}$ precipitation via urease is the most widely used method [5].

The $\mathrm{CaCO}_{3}$ formed by the action of ureolytic bacteria can be used as binders (biocement) in a process known as biocementation [6,7]. Biocement is produced by MICCP in the voids between the particles of a granular material, through the flow of a liquid medium containing microorganisms, urea as a solution of substrate and calcium ions [6]. In this process, the carbonates must be deposited uniformly in the intergranular spaces for proper bonding. When biocementation is carried out in conjunction with other binders, such as lime or Portland cement, the high alkalinity of these materials represents an additional challenge in these applications, where microorganisms with a high tolerance to alkalinity must be used [8].

Biocement may present a more environmentally friendly alternative than conventional cement because it does not generate $\mathrm{CO}_{2}$ in its manufacturing process being also consumed through the metabolic conversion of calcium salts in $\mathrm{CaCO}_{3}$ mineralization. For this reason, MICCP is an effective method for the removal of $\mathrm{CO}_{2}$ from the environment [9], [10]. However, MICCP may not be considered completely environmental friendly, due to ammonium formation during the ureolysis process, which can be toxic to human health and soil microorganisms at high concentrations $[1,11,12]$.

Nevertheless, this problem in the production of biosandstone could be minimized by applying the circular economy concept, the by-product ammonium solution formed can be collected during the cementation process and then stripped and converted using sulfuric acid to ammonium sulfate, which can be used as a soil fertilizer [13]. Following cementation process to remove the aqueous ammonia solution and the

\footnotetext{
* Corresponding author: Carolina Martuscelli, Email: martuscelli.carolina@gmail.com
} 
ammonia adsorbed by the sand grains, Lee et. al, [14] and San Pablo et. al [15] used rinse solutions to remove ammonia from MICCP treated soils, this strategy removed greater than $95.7 \%$ ammonium from aqueous solutions without significant effects on cementation integrity. The results indicate that the use of this methodology can reduce the amount of ammonia to acceptable levels.

Studies on biocementation around the world use preferentially calcite precipitation by bacterial induction and the biocement could widely be applied in many fields. It could be used to modify the properties of soil $[16,17,18]$, to produce new constructions materials $[19,20]$, to improve the mechanical properties (strength, stiffness, cohesion, friction), decrease the permeability of porous materials $[20,8]$ and reinforce or repair construction materials such as cementbased materials or concrete [21-23].

Regarding filamentous fungi there is almost no research, so far, on biocementation using this type of microorganisms. According to our best knowledge, only one work was found [24]. In addition to the potential $\mathrm{CaCO}_{3}$ precipitation by urease-positive fungi, their mycelial structures, and higher biomass when compared to bacteria, indicates that this type of microorganisms can serve as a biological fibre to improve the compressive strength of biosandstones [25].

Therefore, this work proposes the use of two urease-positive fungi, Penicillium chrysogenum MUM 9743 and Neurospora crassa MUM 9208, to promote biocementation of sand. The main goal of this study was to access if filamentous fungi could create the right conditions for the production of biosandstone, opening the possibility to being used in other applications such as biorepair agents of cracks in concrete structures.

\section{Materials and Methods}

\subsection{Fungal strains}

Two fungal urease-positive strains, Penicillium chrysogenum MUM 9743 and Neurospora crassa MUM 9208, were obtained from Micoteca da Universidade do Minho (MUM) culture collection.

\subsection{Sand}

Siliceous natural sand with commercial name of S40/45, from Rio Maior, Portugal, was used to produce biosandstone. Table 1 gives the physical and chemical characteristics particle size distribution of the sand.

\subsection{Cementation medium}

Urea-calcium medium was used to promote calcite precipitation. The cementation medium consisted of Modified Martin broth (MMB) (20 g/L glucose, $5 \mathrm{~g} / \mathrm{L}$ peptone, $2 \mathrm{~g} / \mathrm{L}$ of yeast extract, $1 \mathrm{~g} / \mathrm{L}$ of $\mathrm{K}_{2} \mathrm{PO}_{4}$ and $0.5 \mathrm{~g} / \mathrm{L}$ of $\mathrm{MgSO}_{4}, \mathrm{pH}$ 6.5) supplemented with $2 \%(\mathrm{w} / \mathrm{v})$ urea and $40 \mathrm{mM} \mathrm{CaCl}_{2}$.

\subsection{Urease activity}

Christensen's agar medium ( $1 \mathrm{~g} / \mathrm{L}$ glucose, $1 \mathrm{~g} / \mathrm{L}$ peptone, 12 $\mathrm{mg} / \mathrm{L}$ of phenol red, $2 \mathrm{~g} / \mathrm{L}$ disodium phosphate, $2 \mathrm{~g} / \mathrm{L}$ sodium chloride, $15 \mathrm{~g} / \mathrm{L}$ agar and $20 \mathrm{~g} / \mathrm{L}$ urea) was used for the determination of the presence or absence of the urease enzyme by visual identification of the medium colour, from yellow to pink, when $\mathrm{pH}$ increases due to ammonia production by substrate degradation [26].

The urease activity of fungal strains was determined according to the methodology suggested by Shingha et al. [27], where $20 \mathrm{~mL}$ of modified Christensen agar medium was poured into $90 \mathrm{~mm}$ diameter Petri dishes under aseptic conditions. A mycelial disc of $5 \mathrm{~mm}$ diameter of each fungus was placed on the centre of the modified Christensen agar medium, keeping the mycelium surface attached to the medium surface. Cultures were inoculated at $25{ }^{\circ} \mathrm{C}$ in the dark.

Table 1. Characteristics of sand.

\begin{tabular}{|c|c|c|c|c|c|c|c|c|c|}
\hline \multicolumn{10}{|c|}{ Physical Specifications } \\
\hline \multicolumn{5}{|c|}{$\mathrm{pH}$} & \multicolumn{5}{|l|}{7} \\
\hline \multicolumn{5}{|c|}{ Hardness Mohs } & \multicolumn{5}{|c|}{7} \\
\hline \multicolumn{5}{|c|}{ Whiteness } & \multicolumn{2}{|c|}{$\mathrm{L} * 82.5$} & & & \\
\hline \multicolumn{5}{|c|}{ Non compacted bulk density } & \multicolumn{2}{|c|}{$1.58 \mathrm{~g} / \mathrm{ml}$} & & & \\
\hline \multicolumn{5}{|c|}{ Particle density } & \multicolumn{2}{|c|}{$2.62 \mathrm{Mg} / \mathrm{m}^{3}$} & & & \\
\hline \multicolumn{5}{|c|}{ Refractive index } & \multicolumn{2}{|c|}{1.55} & & & \\
\hline \multicolumn{5}{|c|}{ Moisture } & \multicolumn{2}{|l|}{$3-5 \%$} & & & \\
\hline \multicolumn{10}{|c|}{ Chemical Specification (\%) } \\
\hline $\mathrm{SiO}_{2}$ & $\mathrm{Al}_{2} \mathrm{O}_{3}$ & $\mathrm{Fe}_{2} \mathrm{O}_{3}$ & $\mathrm{CaO}$ & $\mathrm{MgO}$ & $\mathrm{Na}_{2} \mathrm{O}$ & $\mathrm{K}_{2} \mathrm{O}$ & $\mathrm{TiO}_{2}$ & $\mathrm{P}_{2} \mathrm{O}_{5}$ & $\mathrm{MnO}$ \\
\hline 99.4 & 0.05 & 0.025 & 0.02 & 0.06 & 0.02 & 0.02 & 0.02 & 0.01 & 0.00 \\
\hline \multicolumn{10}{|c|}{ Particle Size Distribution } \\
\hline \multicolumn{5}{|c|}{ Sieves $(\mathrm{mm})$} & \multicolumn{5}{|c|}{ Passing (\%) } \\
\hline \multicolumn{5}{|c|}{1.4} & \multicolumn{5}{|c|}{100.0} \\
\hline \multicolumn{5}{|l|}{1.00} & \multicolumn{5}{|l|}{100.0} \\
\hline \multicolumn{5}{|c|}{0.500} & \multicolumn{5}{|l|}{84.0} \\
\hline \multicolumn{5}{|c|}{0.250} & \multicolumn{5}{|l|}{6.0} \\
\hline \multicolumn{5}{|c|}{0.125} & \multicolumn{5}{|l|}{0} \\
\hline \multicolumn{5}{|c|}{$<0.125$} & \multicolumn{5}{|l|}{0} \\
\hline
\end{tabular}


Urease activity was evaluated semi-quantitatively as follows: strong activity (colour in Christensen medium changed to deep pink), moderate activity (pink), weak activity (light pink), and no urease activity (no change of colour). Samples were observed on the third and sixth days after inoculation to evaluate the colour intensity and the speed of the enzymatic activity. The enzymatic activity was classified as fast for any medium change after three days or moderate if the change occurred after six days, regardless the relative intensity of the colour developed in the time course.

\section{$2.5 \mathrm{CaCO}_{3}$ biopreciptation}

Fungal discs $(\mathrm{d}=5 \mathrm{~mm})$ grown on potato dextrose agar (PDA, potato extract $4 \mathrm{~g} / \mathrm{L}$, dextrose $20 \mathrm{~g} / \mathrm{L}$ and $15 \mathrm{~g} / \mathrm{L}$ agar) were transferred to plates with Modified Martin agar (MBA), supplemented with $2 \%(\mathrm{w} / \mathrm{v})$ urea, $40 \mathrm{mM} \mathrm{CaCl}_{2}$, and grown at 25 ㅇ for seven days. A control plate without fungal strain was incubated at the same conditions. Samples $(5 \times 5 \mathrm{~mm})$ of each strain were fixed on double-sided carbon adhesive tape (PELCO Tabs TM) on standards aluminium stubs and were dried in an incubator for 3 days at $50^{\circ} \mathrm{C}$.

Materials mounted on stubs were coated with $2.5 \mathrm{~nm}$ of gold. The morphology and chemical constituents of crystals formed by the fungal strains were measured Scanning Electron Microscopy by (Phenom Prox SEM) and Energy Dispersive (EDS) via Phenom Prox EDS with $15 \mathrm{kV}$. Three samples of each biosandstone formed were observed.

\subsection{Biocementation of sand}

Fungal biomass of $P$. crhrysogenum MUM 9743 and $N$. crassa MUM 9208 from 7 days old cultures grown in PDA, at $25 \stackrel{\circ}{\circ}$, were harvested and homogenized with $5 \mathrm{~mL}$ of supplemented MMB. The obtained biomass suspensions were transferred onto Erlenmeyer's with $70 \mathrm{~mL}$ of supplemented $\mathrm{MMB}$ and left to grow at $25^{\circ} \mathrm{C}$ for three days under shaking conditions. The resulting products were mixed with sterilized sand and polymeric sterile tubes, were packed uniformly with it. The tubes were positioned vertically and a tube without fungal biomass was maintained in the same conditions as abiotic control.

The sand tubes were incubated at $25^{\circ} \mathrm{C}$ and moisturised until saturation with $10 \mathrm{~mL}$ supplemented MMB every $48 \mathrm{~h}$ during 14 days. At the end of the experiment, the tubes were dried at $50{ }^{\circ} \mathrm{C}$ for five days and the samples were observed under $\mathrm{SEM} / \mathrm{EDS}$ to analyse the fungal grown on the samples.

\subsection{Compressive test}

The samples had their compressive strengths determined using a compression rate of $0.5 \mathrm{~mm} / \mathrm{min}$, for this, they were cut in parallel face cylinders respecting the height ratio twice the diameter.

\section{Results and discussion}

\subsection{Urease activity}

The urease activity was observed every 3 days as described in the methodology, regarding the developing colour of the culture plates. Both studied strains ( $P$. chrysogenum MUM 9743 and N. crassa MUM 9208) presented strong and rapid urease activity and biomass production. Therefore, they were able to induce calcium carbonate precipitation by ureolytic process.

The colour change of the medium from yellow $(\mathrm{pH} \mathrm{6.5)} \mathrm{to}$ deep pink (Fig. 1) indicates the ureolytic activity of the fungi, through the use of the phenol red $\mathrm{pH}$ indicator, which has a deep pink colour at $\mathrm{pH}$ above 8.3.

\section{2 $\mathrm{CaCO}_{3}$ biopreciptation}

When cultivated on supplemented MMA, the fungal strains grew well not showing changes in their macromorphologies.

No precipitated crystals were observed in the control plate. Both samples showed fungal morphology with hyphae that penetrate in the medium and presented relevant aerial mycelium. Crystals, tightly associated with hyphae and precipitated by the fungal strains grown in supplemented MMA, were observed by SEM (Fig. 2). Figure 2a and b show hyphae of $P$. chrysogenum MUM 9743 and $N$. crassa MUM 9208 forming crystals of $\mathrm{CaCO}_{3}$, respectively.

$a$

b
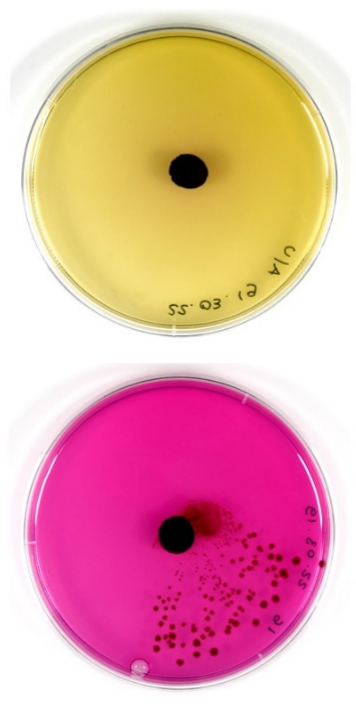

C

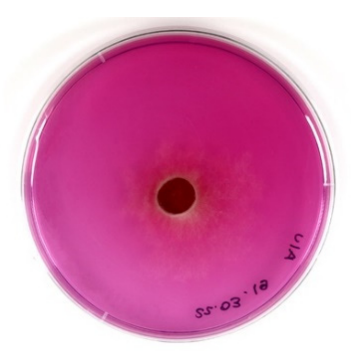

Figure 1. Urease Activity after 3 days of incubation (a) Control, (b) $P$. chrysogenum MUM 9743 and (b) N. crassa MUM 9208.

Biominerals formed in the presence of $P$. chrysogenum MUM 9743 presented clusters of larger crystals than those formed in the presence of $N$. crassa MUM 9208. The Fig. 2a shows a typical crystal formed in the samples with $P$. chrysogenum MUM 9743 showed a mineral with $35.4 \mu \mathrm{m}$ diameter. The average diameter present on samples to $P$. chrysogenum MUM 9743 was $39.6 \mu \mathrm{m}$ and it was possible observed 3 clusters of crystals. Neurospora crassa MUM 9208 show crystals with a maximum diameter of $26.3 \mu \mathrm{m}$ with $18.3 \mu \mathrm{m}$ as diameter average. In addition to the formed crystals and to 
the same experimental conditions, $P$. chrysogenum MUM 9743 exhibits much more biomass than N. crassa MUM 9208.

a

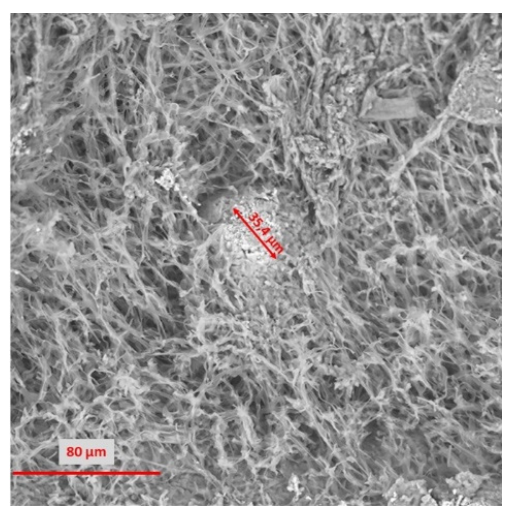

b

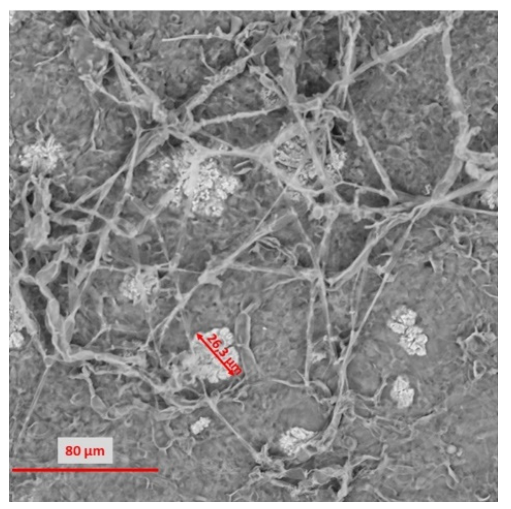

Figure 2. Scanning Electron Micrographs of $\mathrm{CaCO}_{3}$ crystals precipitated by fungal strains grown in supplemented MMA. (a) $P$. chrysogenum MUM 9743 and (b) N. crassa MUM 9208.
The minerals induced by both strains (Figa and c) were analysed by Energy Dispersive Spectroscopy (EDS). EDS results showed that $\mathrm{CaCO}_{3}$ and oxygen were the main elements present in the formed precipitates from both fungal strains (Fig. $3 b$ and d). In addition, results from crystal morphologies were very similar to the ones obtained by Fang et al. [24] and Li et al, [28], who suggested the bioprecipitation of $\mathrm{CaCO}_{3}$ by strains belonging to the same species tested in this study.

\subsection{Fungal biosandstone}

The fungal strains were used to test their ability to precipitate $\mathrm{CaCO}_{3}$ and promote sand biocementation.

The control sample, without fungal biomass, was completely broken after being removed from the polymeric mould (Fig. 4a). The urease-positive fungi used in the work were able to promote sand cementation (Fig. $4 \mathrm{~b}$ and c) making solid materials, biosandstones in 14 days.

\subsection{Compressive Strength}

The compressive strength and density of the biosandstone formed through biocementation of sand by $P$. chrysogenum MUM 9743 was $66.5 \mathrm{kPa}, 2.05 \mathrm{~g} / \mathrm{cm}^{3}$ and that by $N$. crassa MUM 9208 was $50 \mathrm{kPa}, 1.75 \mathrm{~g} / \mathrm{cm}^{3}$.

The increase in density presented by the biosandstone formed by $P$. chrysogenum when compared to the density of the biosandstone formed by $N$. crassa is due to the higher production of $\mathrm{CaCO}_{3}$, which is also responsible for the difference between the compressive strength of the formed biosandstones.

a
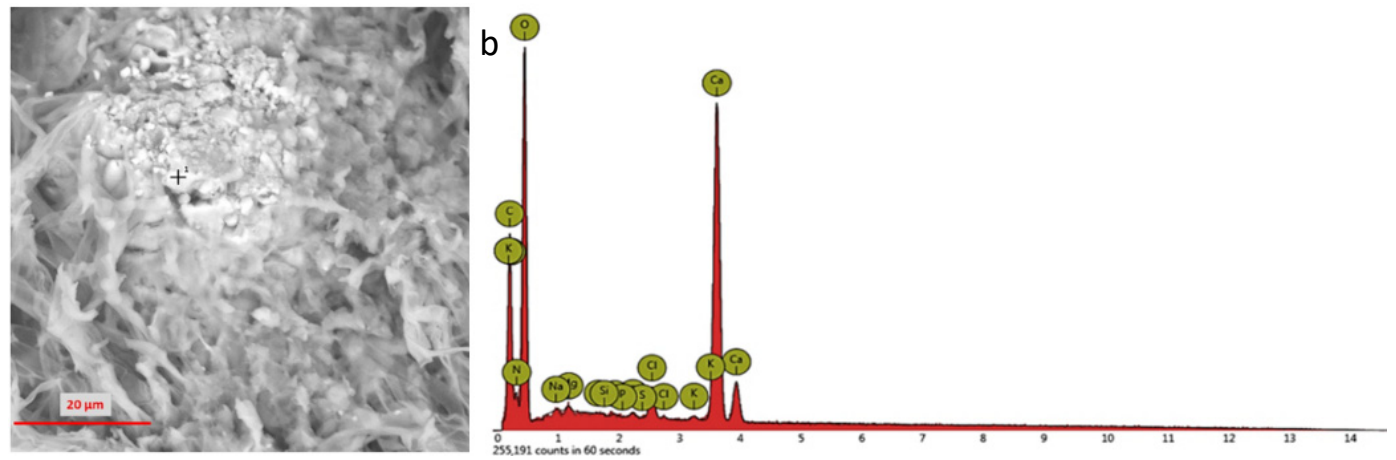

C
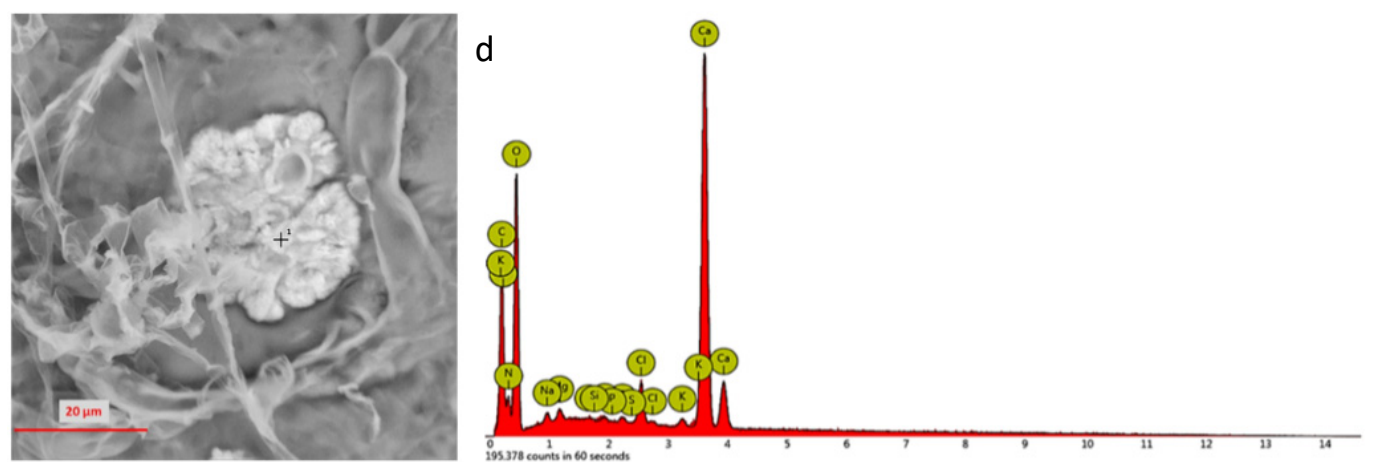

Figure 3. Energy Dispersive Spectroscopy of minerals formed in supplemented MMA after incubation with fungi strains. (a,b) P. chrysogenum MUM 9743 and (c,d) N. crassa MUM 9208. 

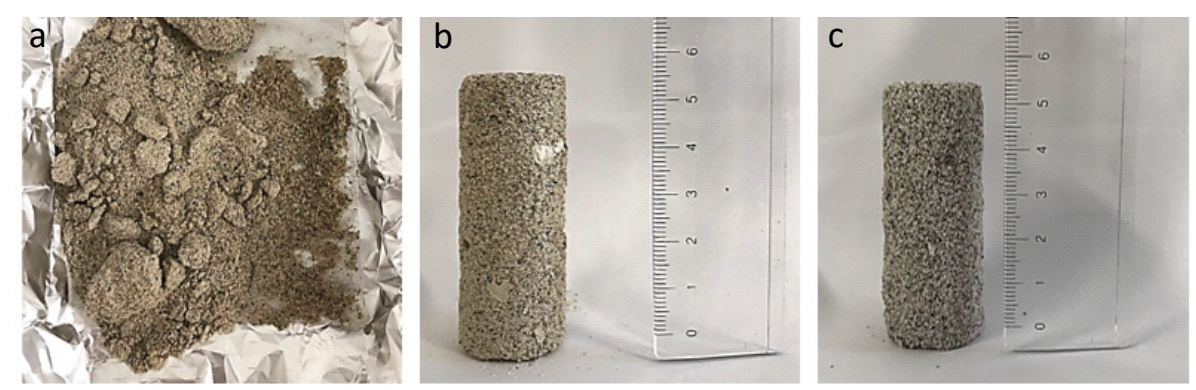

Figure 4. Biocementation of sand. (a) Control, (b) Biosandstone formed with P. chrysogenum MUM 9743 and (c) Biosandstone formed with N. crassa MUM 9802.
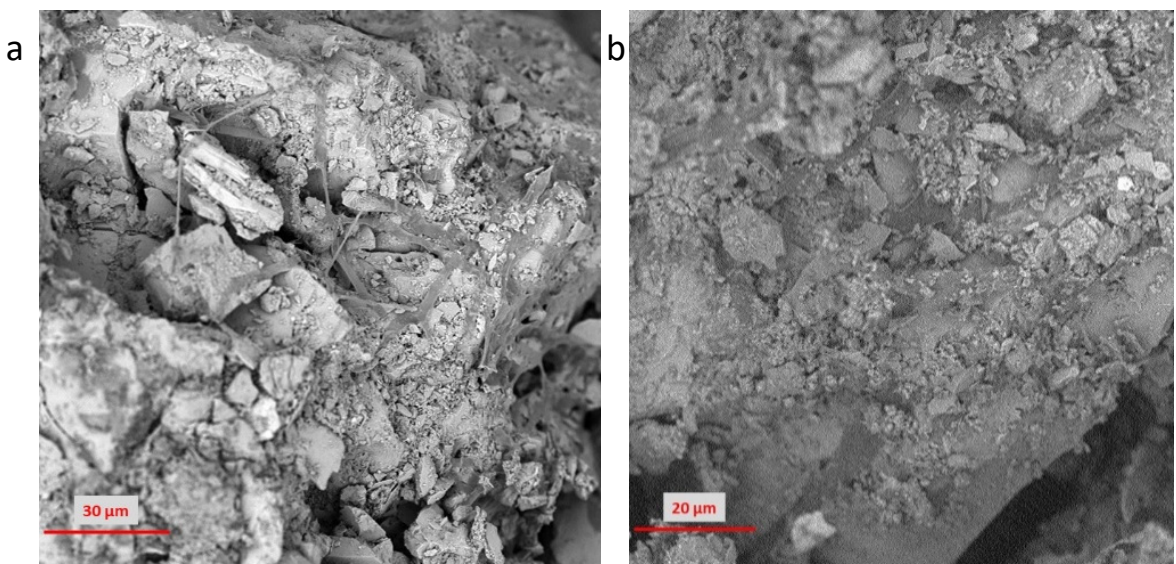

Figure 5. Scanning Electron Micrographs of growth within biosandstones. (a) P. crysogenum MUM 974 with magnification of 2000x and (b) N. crassa MUM 9208 with magnification of 3000x.

The growth presented by the strains within the material was different (Fig. 5). P. chrysogenum MUM 9743 has shown higher growth (Fig. 5a) which may have led to different resistance results of the formed materials, as the fungal mycelia behaved like microfibers promoting increased mechanical resistance.

The compressive strength results found for $P$. chrysogenum MUM 9743 for 14 days were similar to those observed by adding $4 \%$ cement to the soft soil [29] and to those resulting from bacterial sand cementation (Sporosarcina pasteurii) for 7 days [20]. Although the sand consolidation strengths applying our fungi at 14 days are lower than bacteria, which can be due to a slower biocement development when fungi are used in comparison with bacteria. Thus, maybe higher time span is required for an efficient biocement when fungi are used.

\section{Conclusions}

The fungal strains, $P$. chrysogenum MUM 9743 and N. crassa MUM 9208, used in this study were able to induce the precipitation of $\mathrm{CaCO}_{3}$ and promote the biocementation of sand forming biosandstones. Thus, this work has demonstrated the potential of the urease-positive fungi to produce as yet weak (50-66 $\mathrm{kPa})$ biosandstones using a natural microbial process.

In the present study, the compressive strength found for the biosandstone produced was far lower compared to the strength of conventional materials. However, studies with the use of fungi in the biocementation processes are quite scarce and recent, so the methodologies for the use of these microorganisms need to be established and optimized so that better results can be achieved in the development of ecoefficient building materials and for a better understanding of the biocementation process by fungi.

It is concluded that multidisciplinary studies like this one involving the areas of construction materials and mycology can be a good strategy for the development of ecologically more sustainable building materials.

\section{Acknowledgements}

This study was supported by the Portuguese Foundation for Science and Technology (FCT) under the scope of the strategic funding of UIDB/04469/2020 unit and BioTecNorte operation (NORTE-01-0145-FEDER-000004) funded by the European Regional Development Fund under the scope of Norte2020 Programa Operacional Regional do Norte.

\section{CRediT authorship statement}

Carolina Martuscelli - Conceptualization, Methodology, Validation, Investigation, Writing - original draft.

Célia Soares- Conceptualization, Methodology, Resources, Writing - review and editing.

Nelson Lima- Conceptualization, Methodology, Resources, Writing - review and editing, Supervision, Funding acquisition.

Aires Camões - Conceptualization, Methodology, Resources, Writing - review and editing, Supervision. 


\section{References}

[1] M. Seifan, A. Samani, A. Berenjian, Bioconcrete: next generation of self-healing concrete. Appl Microbiol Biotechnol (2016) 100: 25912602. https://doi.org/10.1007/s00253-016-7316-z

[2] D. Kumari, X.Y. Qian, X. Pan, V. Achal, Q. Li, G.M. Gadd, Microbiallyinduced carbonate precipitation for immobilization of toxic metals. Adv Appl Microbiol (2016) 94: 79-108. https://doi.org/10.1016/bs.aambs.2015.12.002

[3] S. Weiner, P.M. Dove, An Overview of biomineralization processes and the problem of the vital effect. Rev Mineral Geochem (2003) 54: 1-29. https://doi.org/10.2113/0540001

[4] D. Mujah, M.A. Shahin, L. Cheng, State-of-the-art review of biocementation by microbially induced calcite precipitation (MICP) for soil stabilization. Geomicrobiol J (2016) 34: 524-537. https://doi.org/10.1080/01490451.2016.1225866

[5] A.I. Omoregie, R.H. Ginjom, P.M. Nissom, Microbially induced carbonate precipitation via ureolysis process: a mini-review. Trans. Sci. Technol. (2018) 5: 245-256.

[6] De Muynck, W., De Belie, N., Verstraete, W., Microbial carbonate precipitation in construction materials: a review. Ecol. Eng. (2010) 36(2): 118-136. https://doi.org/10.1016/i.ecoleng.2009.02.006

[7] Q. Chunxiang, P.A.N. Qingfeng, W. Ruixing, Cementation of sand grains based on carbonate precipitation induced by microorganism. Sci China Technol Sci (2010) 53: 2198-2206. https://doi.org/10.1007/s11431-009-3189-z

[8] V. Achal, A. Mukherjee, D. Kumari, Q. Zhang, Biomineralization for sustainable construction - a review of processes and applications. Earth Sci Rev (2015) 148: 1-17. https://doi.org/10.1016/i.earscirev.2015.05.008

[9] A.F. Alshalif, J. M. Irwan, N. Othman, A. Al-Gheethi, A. Hassan, Potential of carbonic anhydrase and urease bacteria for sequestration of $\mathrm{CO} 2$ into aerated concrete. MATEC Web of Conf., Y. Haryati, M.Y.N. Zurairahetty, I.I. Syahrizal (Eds.) Jodor (Malaysia), 2728 August 2018, MATEC Web of Conf. 250: 03004. https://doi.org/10.1051/matecconf/201825003004

[10] A.C. Mitchell, K. Dideriksen, L.H. Spangler, A.B. Cunningham, R. Gerlach, Microbially enhanced carbon capture and storage by mineral-trapping and solubility-trapping. Environ Sci Technol (2010) 44:5270-5276. https://doi.org/10.1021/es903270w

[11] P. Anbu, C.H. Kang, Y.J. Shin, J.S. So, Formations of calcium carbonate minerals by bacteria and its multiple applications. Springerplus (2016) 5: 250. https://doi.org/10.1186/s40064-016-1869-2

[12] S.G. Choi, J. Chu, R.C. Brown, K.J. Wang, Z.Y. Wen, Sustainable biocement production via microbially induced calcium carbonate precipitation: use of limestone and acetic acid derived from pyrolysis of lignocellulosic biomass. ACS Sustain Chem Eng (2017) 5 (6): 51835190. https://doi.org/10.1021/acssuschemeng.7b00521

[13] S.K. Pradhan, A. Mikola, R. Vahala, Nitrogen and phosphorus harvesting from human urine using a stripping, absorption, and precipitation process. Environ Sci Technol (2017) 51: 5165-5171. https://doi.org/10.1021/acs.est.6b05402

[14] M. Lee, M.G. Gomez, A.C.M. San Pablo, C.M. Kolbus, C.M.R. Graddy, J.T. DeJong, D.C. Nelson, Investigating Ammonium By-product Removal for Ureolytic Bio-cementation Using Meter-scale Experiments. Sci Rep (2019) 9:18313. https://doi.org/10.1038/s41598-019-54666-1

[15] A.C.M. San Pablo, M.Lee, C.M.R. Graddy, C.M. Kolbus, M. Khan, A.Zamani, N. Martin, C. Acuff, J.T. DeJong, M.G. Gomez, D.C. Nelson, Meter-scale Bio-cementation Experiments to Advance Process Control and Reduce Impacts: Examining Spatial Control, Ammonium By-product Removal, and Chemical Reductions. J Geotech Geoenviron Eng (2020) 146(11): 04020125. https://doi.org/10.1061/(ASCE)GT.1943-5606.0002377

[16] S.W. Ng, M.L. Lee, S.L. Hii, An overview of the factors affecting microbial-induced calcite precipitation and its potential application in soil improvement. World Acad Sci Eng Technol (2012) 62:723-729. https://doi.org/10.5281/zenodo.1084674

[17] V. Ivanov, J. Chu, Applications of microorganisms to geotechnical engineering for bioclogging and biocementation of soil in situ. Rev Environ Sci Biotechnol (2008) 7:139-153. https://doi.org/10.1007/s11157-007-9126-3

[18] L. Cheng, M.A. Shahin, R. Cord-Ruwisch, Surface percolation for soil improvement for soil improvement by biocementation utilizing in situ enriched. Geomicrobiol J (2017) 34(6):546-556. https://doi.org/10.1080/01490451.2016.1232766
[19] S.E. Lambert, D.G. Randall, Manufacturing bio-bricks using microbial induced calcium carbonate precipitation and human urine. Water Res (2019) 160: 158- 166. https://doi.org/10.1016/j.watres.2019.05.069

[20] D. Bernardi, J.T. DeJong, B.M. Montoya, B.C. Martinez, Bio-bricks : Biologically cemented sandstone bricks. Constr Build Mater (2014) 55: 462-469. https://doi.org/10.1016/j.conbuildmat.2014.01.019

[21] S. Joshi, S. Goyal, A. Mukherjee, M. S. Reddy, Microbial healing of cracks in concrete: a review. J Ind Microbiol Biotechnol (2017) 44(11):1511-1525. https://doi.org/10.1007/s10295-017-1978-0

[22] K. Van Tittelboom, N. De Belie, W. De Muynck, W. Verstraete, Use of bacteria to repair cracks in concrete. Cem Concr Res (2010) 40: 157166. https://doi.org/10.1016/j.cemconres.2009.08.025

[23] S. Ruan, J. Qiu, Y. Weng, Y. Yang, E.H. Yang, J. Chu, C. Unluer, The use of microbial induced carbonate precipitation in healing cracks within reactive magnesia cement-based blends. Cem Concr Res (2019) 115: 176-188. https://doi.org/10.1016/j.cemconres.2018.10.018

[24] C. Fang, D. Kumari, X. Zhu, V. Achal, Role of fungal-mediated mineralization in biocementation of sand and its improved compressive strength. Int Biodeterior Biodegrad (2018) 133: 216-220. https://doi.org/10.1016/j.ibiod.2018.07.013

[25] S. Bindschedler, G. Cailleau, E. Verrecchia, Role of fungi in the biomineralization of calcite. Miner (2016) 6(2):41. https://doi.org/10.3390/min6020041

[26] W.B. Christensen, Urea decomposition as a means of differentiating Proteus and Paracolon cultures from each other and from Salmonella and Shigella types. J Bacteriol (1946) 52:461-466. https://doi.org/10.1128/JB.52.4.461-466.1946

[27] B.B. Shingha, A. Suzuki, H.N-D. Pham, S. Inatomi, Adaptation of ammonia fungi to urea enrichment environment, J Agric Technol (2012) 8(81):173-189.

[28] Q. Li, L. Csetenyi, G.I. Paton, G.M. Gadd, $\mathrm{CaCO} 3$ and $\mathrm{SrCO} 3$ bioprecipitation by fungi isolated from calcareous soil. Environ Microbiol (2015) 17:3082-3097. https://doi.org/10.1111/14622920.12954

[29] D.R. Dias, G. Camarini, M.G. Miguel, Preliminary laboratory tests to study the increase of strength in samples of soft soils with cement, for treatments using Dry-Mix System. Proc. 4th Inter Conf Grout Deep Mix, L. F. Johnsen, D.A. Bruce, M.J. Byle (Eds), New Orleans (United States), 15-18 February 2012, ASCE Geotechnical Special Publication 228, 2012, 454-462. https://doi.org/10.1061/9780784412350.0031 